\title{
VI. A new method of treating correlated averages
}

\author{
Professor F. Y. Edgeworth M.A. D.C.L.
}

To cite this article: Professor F. Y. Edgeworth M.A. D.C.L. (1893) VI. A new method of treating correlated averages, Philosophical Magazine Series 5, 35:212, 63-64, DOI: 10.1080/14786449308620380

To link to this article: http://dx.doi.org/10.1080/14786449308620380

曲 Published online: 08 May 2009.

Submit your article to this journal $\sqsubset$

Џll Article views: 3

Q View related articles $匚$ 


\section{$\left[\begin{array}{ll}63 & ]\end{array}\right.$}

VI. A New Method of treating Correlated Averages.

By Professor F. Y. EDGEWoRTH, M.A., D.C.L.*

TTHE following is a simpler method of solving one of the 1 problems treated in a former paper relating to correlated averagest. Taking the case of three variables for convenience of enunciation, let us put for the exponent (of the expression for the probability that any particular values of the variables will be associated)

$$
\mathrm{R}=a x^{2}+b y^{2}+c z^{2}+2 f y z+2 g x z+2 h x y .
$$

And let it be required to determine the coefficients $a, b, c, \&$.

The most probable values of $y$ and $z$ corresponding to any assigned value of $x$, say $x^{\prime}$, are deduced from the equations

$$
\left\{\begin{array}{l}
b y+f z+h x^{\prime}=0 \\
c z+f y+g x^{\prime}=0 .
\end{array}\right.
$$

The values of $y$ and $z$ determined from these equations may indeed diverge widely from the particular values corresponding in any one specimen to $x^{\prime}$. But if we take a number of specimens, it becomes more true $\$$ that

$$
\left\{\begin{array}{l}
b \mathrm{~S} y+f \mathrm{~S} z+h \Sigma x^{\prime}=0, \\
c \mathrm{~S} z+f \mathrm{~S} y+g \Sigma x^{\prime}=0 .
\end{array}\right.
$$

Dividing each equation by the sum of the assigned values $\Sigma x^{\prime}$, we have

$$
\left\{\begin{array}{l}
h \rho_{12}+f \rho_{13}+h=0 \\
c \rho_{13}+f \rho_{12}+g=0 ;
\end{array}\right.
$$

where $\rho_{12}, \rho_{13}$ mean (as in the former paper) the coefficients of correlation pertaining to each couple of organs (Mr. Galton's $r$ ).

By similarly assigning values of $y$ and of $z$, and observing the associated values of the other variables, we obtain six (in general $n(n-1)$ ) equations for the sought coefficients $a, b, \ldots g, h$; which, being rearranged, are as follows :-

$$
\left.\begin{array}{l}
\rho_{12} a+\rho_{23} g+h=0, \\
\rho_{31} a+g+\rho_{23} h=0 ; \\
\rho_{23} b+f+\rho_{31} h=0, \\
\rho_{12} b+\rho_{31} f+h=0 ; \\
\rho_{31} c+\rho_{12} f+g=0, \\
\rho_{23} c+f+\rho_{12} g=0 .
\end{array}\right\}
$$

* Communicated by the Author.

$\dagger$ Phil. Mag. August 1892.

$\ddagger$ Cf. loc. cit. p. 191 et seq. 
A solution of this system is afforded by putting $a, b, c$ each proportional to one of the principal minors, and $f, g, h$ each to a certain one of the other three minnrs, of the following determinant :-

$\left|\begin{array}{lll}1, & \rho_{12}, & \rho_{31} \cdot \\ \rho_{12}, & 1 & \rho_{23}, \\ \rho_{31}, & \rho_{23}, & 1,\end{array}\right|$

For call the three minors formed by omitting successively each constituent in the first row $\mathrm{a}, \mathrm{h}, \mathrm{g}$. By a well-known theorem*, if each of these minors is multiplied by the corresponding constituent in the rows other than the first, the sum of these products $=0$.

That is

$$
\left.\begin{array}{l}
\rho_{12} \mathrm{a}+\mathrm{h}+\rho_{23} \mathrm{~g}=0 \\
\rho_{31} \mathrm{a}+\rho_{23} \mathrm{~h}+\mathrm{g}=0
\end{array}\right\}
$$

Thus the first two of the above-written six equations are satisfied. By parity of reasoning, if we put, for $b$, the principal minor $b$, for $c$, $c$, and, for $f$, the minor $f$, obtained by omitting the row and column containing (either) $\rho_{23}$, the remaining four equations are satisfied. The proposed system of proportional values is therefore $a$ solution. And since the equations are simple, it is the solution.

We have thus obtained by a simpler method than before the solution of the problem $t$ : given the values of some of the variables, what are the most probable values of the other variables? For the proportionate values of the coefficients $a, b, \ldots, q, h$ having been ascertained, we have only to substitute in $\mathbf{R}$ the given values of one or more variables, e.g. $z^{\prime}$; and for the most probable values of the remaining variables we have the equations

$$
\left(\frac{d \mathrm{R}}{d x}\right)_{z=z^{\prime}}=0 ;\left(\frac{d \mathrm{R}}{d y}\right)_{z=z^{\prime}}=0 .
$$

But we have not obtained a solution of the second problem $\ddagger$ : given the values of some of the variables, what is the law of dispersion for the remaining ones? For in order to solve this problem we require the absolute values of the coefficients. I do not see how to obtain these, except by the method before adopted, viz., obtaining the integrals of the expression

$$
\mathrm{J} e^{-\left(a x x^{2}+b y^{2}+c z^{2}+2 f y z+2 g x z+2 h x y\right)}
$$

with respect to all but two, and all but one, of the variables.

Balliol College, Oxford.

* Salmon, 'Higher Algebra,' lesson iv. article 27.

$\dagger$ Generalizing the statement given in the former paper, p. 190.

$\neq$ Generalizing the statement given in the former paper, p. 190. 